\title{
Improved patient outcome with smoking cessation: when is it too late?
}

This article was published in the following Dove Press journal:

International Journal of COPD

29 April 2011

Number of times this article has been viewed

Jane $\mathrm{Wu}^{\prime}$

Don D $\operatorname{Sin}^{1,2}$

'Department of Medicine (Division of Respirology), The University of British Columbia, Vancouver, BC, Canada;

${ }^{2} U B C$ James Hogg Research Laboratory, Providence Heart and Lung Institute, St. Paul's Hospital, Vancouver, BC, Canada

Correspondence: Don D Sin St. Paul's Hospital, Station 8B Room 8442, I08I Burrard Street, Vancouver, BC V6Z IY6, Canada $\mathrm{Tel}+\mathrm{I} 6048068395$

Fax + I 6048068722

Email don.sin@hli.ubc.ca
Abstract: Smoking is the leading modifiable risk factor for chronic obstructive pulmonary disease (COPD), cardiovascular disease (CVD), and lung cancer. Smoking cessation is the only proven way of modifying the natural course of COPD. It is also the most effective way of reducing the risk for myocardial infarction and lung cancer. However, the full benefits of tobacco treatment may not be realized until many years of abstinence. All patients with COPD, regardless of severity, appear to benefit from tobacco treatment. Similarly, patients with recent CVD events also benefit from tobacco treatment. The risk of total mortality and rate of recurrence of lung cancer is substantially lower in smokers who manage to quit smoking following the diagnosis of early stage lung cancer or small cell lung cancer. Together, these data suggest that tobacco treatment is effective both as a primary and a secondary intervention in reducing total morbidity and mortality related to COPD, CVD, and lung cancer. In this paper, we summarize the evidence for tobacco treatment and the methods by which smoking cessation can be promoted in smokers with lung disease.

Keywords: COPD, lung cancer, tobacco treatment, smoking cessation

\section{Introduction}

Tobacco smoking is a leading cause of mortality worldwide, killing one in 10 adults and causing 5 million deaths annually. ${ }^{1,2}$ Nearly 3000 people die from tobacco-related complications each day. By 2030, if the current smoking trends continue, tobacco will be responsible for one in six deaths and account for more than 10 million deaths per annum. ${ }^{2}$ Tobacco also exacts a colossal financial toll, leading to an annual global net loss of US\$200 billion, owing in large part to loss in productivity and increased use of health services. ${ }^{2}$ Unfortunately, about a third of the entire male adult global population are daily smokers. The rates are the highest in East Asia and other parts of the Western Pacific region, where nearly two out of three adult males are smokers. ${ }^{3}$ One-third of all tobacco worldwide is consumed in one country, China, where the estimated smoking rate in men is $67 \%$ and in women is $4 \%$. Today, there are close to 300 million Chinese smokers, which is more than the entire US population and, collectively, they consume an estimated 1.7 trillion cigarettes per year - or 3 million cigarettes per minute. ${ }^{3}$ It is estimated that smoking will eventually kill a third of the young Chinese men living today (under the age of 30 years). ${ }^{3}$ Although smoking rates are falling in the Western world, regrettably they are on the rise in the developing nations. Nearly $80 \%$ of smoking-related morbidity and mortality are accounted for by three conditions: 1) cardiovascular disease (CVD), which is responsible for $\sim 40 \%$ of all smokingrelated deaths; 2) lung cancer, which accounts for $20 \%$ of all smoking-related deaths; 
and 3) chronic obstructive pulmonary disease (COPD), which accounts for another $20 \%$ of all smoking-related mortality. ${ }^{1}$ In this paper, we will examine the relationship of cigarette smoking to these conditions and determine the impact tobacco treatment has in patients who have already developed these smoking-related conditions.

\section{General benefits of smoking cessation}

The benefits of smoking cessation in CVD are almost immediate. Within 24 hours of smoking cessation, there are significant improvements in blood pressure and heart rate. ${ }^{4}$ Within one year of abstinence, the risk of cardiovascular events (eg, myocardial infarction [MI] and stroke) is reduced by half (compared with continued smoking). Between 5 and 15 years post-smoking, the risk of stroke and coronary heart disease is "normalized" to that of never smokers. ${ }^{4}$ On the other hand, the benefits of tobacco treatment on the risk of lung cancer take much longer to achieve. The risk of lung cancer declines steadily following smoking cessation such that after about 10 years of abstinence, the risk of lung cancer is between $30 \%$ and $50 \%$ of that for continued smokers. ${ }^{5}$ However, even after decades of smoking cessation, the risk of lung cancer may never reach that of never smokers. The benefits of tobacco treatment to COPD progression are measurable within the first year of abstinence and are particularly striking in female smokers who manage to quit smoking. ${ }^{6}$ After several years of smoking cessation, the rate of decline in lung function becomes similar to that of never smokers. ${ }^{7}$ However, because the lung function lost during the time the patient smoked is never fully recovered and because lung function declines with age (even in nonsmokers), COPD patients may develop additional symptoms and progress to a higher COPD severity class, even after many years of smoking abstinence. ${ }^{8}$

\section{The benefits of smoking cessation in patients with established COPD}

The landmark studies evaluating the effect of tobacco treatment on cardiopulmonary health outcomes are summarized in Table 1. Although the traditional teaching has been that only $10 \%-15 \%$ of smokers develop COPD,${ }^{9}$ data from large epidemiological studies indicate that the risk is nearly $50 \%,{ }^{10}$ suggesting that one in two smokers, if they live long enough, will eventually develop COPD. In the overall population, the population-attributable risk of COPD related to smoking is approximately $45 \% .^{10,11}$ However, many of these patients never present to physicians' attention because they are asymptomatic or minimally symptomatic. ${ }^{12}$ Among clinically symptomatic patients with COPD, the populationattributable risk related to smoking is much higher. ${ }^{13}$

Smoking cessation is the only proven way of slowing down disease progression in COPD. One of the landmark studies that examined the effects of tobacco treatment on COPD progression was the Lung Health Study (LHS). ${ }^{7}$ In the LHS, 5887 current smokers with mild to moderate COPD (Global initiative for chronic Obstructive Lung Disease, GOLD, Stages 1 and 2) were randomized to one of three treatment arms: 1) usual care, 2) smoking intervention plus the inhaled bronchodilator ipratropium, or 3) smoking intervention plus an inhaled placebo and were followed for 5 years. ${ }^{7}$ The tobacco treatment consisted of: physician recommendation against smoking, aggressive smoking cessation counseling by a health educator 12 times over a 10 -week period, and nicotine replacement therapy using nicotine gum (Nicorette; Marion Merrell Dow Inc, Kansas City, MO). The smokers were followed at 4-month intervals to check on their smoking status and to institute relapse treatment for those who failed to quit or had relapsed. Smokers who relapsed were treated aggressively with the above measures and by teaching them coping strategies for relieving stress and weight gains. Compliance with smoking cessation was determined by self-report and verified by measuring expired carbon monoxide (at each visit) and salivary cotinine levels (at each annual visit). Cotinine levels greater than $20 \mathrm{ng} / \mathrm{mL}$ were classified as smokers. ${ }^{14}$ In those who were taking nicotine replacement therapy, exhaled carbon monoxide concentrations of greater than $10 \mathrm{ppm}$ were considered as smokers (as the use of salivary cotinine levels was not reliable in these participants). All participants were followed in person annually for 5 years, and during each annual visit, spirometry measurements were performed and their health service utilization including hospitalizations as well as vital status data were captured. Over the 5 years of follow-up, $22 \%$ became sustained quitters (ie, classified as a quitter at all five follow-up annual visits) in the two groups that received special intervention for tobacco treatment. ${ }^{7}$ In contrast, only $5 \%$ of the smokers in the usual care arm became sustained quitters over the 5 years. $^{7}$ Interestingly, those who were sustained quitters at year 5 remained sustained quitters over 11 years of follow-up, while those who were continuous smokers remained continuous smokers at year $11 .^{15}$ These data highlight the importance of effecting and maintaining abstinence over the first few years.

Importantly, in the LHS, smoking cessation was associated with a slower decline in lung function and reduced risk of hospitalization and total mortality. Participants in the special 
intervention group plus a placebo inhaler, who became sustained quitters, experienced a forced expiratory volume in one second $\left(\mathrm{FEV}_{1}\right)$ decline of only $34 \mathrm{~mL} /$ year. In contrast, those who continued to smoke experienced an $\mathrm{FEV}_{1}$ decline of $63 \mathrm{~mL} /$ year. ${ }^{7}$ Thus, smoking cessation nearly halved the rate of descent in $\mathrm{FEV}_{1}$ in patients with mild to moderate COPD. Smokers who quit and then took up smoking again had $\mathrm{FEV}_{1}$ declines that fell somewhere in between that of sustained quitters and continued smokers. ${ }^{7}$ Interestingly, female continued smokers experienced a faster decline in lung function compared with male continued smokers for the amount of cigarettes they smoked. ${ }^{16}$ However, female smokers experienced larger gains in lung function when they stopped smoking compared with male quitters. ${ }^{6}$ Smokers who quit and re-initiated smoking at multiple times experienced a slower decline in $\mathrm{FEV}_{1}$ than continued smokers, for the same number of cigarettes they smoked. ${ }^{16}$ Together, these data suggest that smoking cessation significantly reduces disease progression in mild to moderate COPD and that even having multiple relapses is better than continued smoking in terms of disease progression. Tobacco treatment is particularly important for women, who appear to have increased susceptibility to disease progression with continued smoking but also derive larger benefits with smoking cessation compared with male smokers.

\section{Tobacco treatment and mortality}

During the 5 years of the LHS follow-up, 149 participants (representing 2.5\% of the cohort) died. The leading cause of mortality was lung cancer (representing $38.3 \%$ of the total deaths), followed by CVD (representing $24.8 \%$ of the total deaths). Smoking cessation was associated with a $32 \%$ reduction in all-cause mortality at 5 years of follow-up. ${ }^{17}$ This trend persisted over 14.5 years of follow-up. Sustained quitters had a total mortality rate that was $42 \%$ lower than that of continued smokers and intermittent quitters/smokers had a $30 \%$ lower mortality rate than that of continued smokers. ${ }^{5}$ The salutary effect of smoking cessation was most pronounced on CVD mortality, reducing it by $45 \%$. Surprisingly, in this study, smoking cessation did not have any significant impact on mortality or hospitalization related to lower respiratory tract infection or COPD progression. However, in the Multiple Risk Factor Intervention Trial (MRFIT) ${ }^{18}$ intervention consisting of smoking cessation, and blood pressure and serum cholesterol treatment, was associated with a significant $20 \%$ reduction in mortality from respiratory causes. ${ }^{18}$ Smoking cessation reduces mortality from lung cancer. ${ }^{7}$ Importantly, the risk of lung cancer mortality with smoking is modified by lung function (or COPD severity) in men, but less so in women. ${ }^{19}$ In men, continuous smokers have increased risk for lung cancer mortality for every category of COPD severity. However, in sustained quitters and intermittent smokers, the risk is not significantly increased until $\mathrm{FEV}_{1}$ is below $80 \%$ of pre$\operatorname{dicted}^{20}$ (see Figure 1). In both men and women, smoking cessation reduces deaths from lung cancer by over $50 \%{ }^{5}$ However, intermittent quitters/smokers do not experience a significant decline in mortality rates from lung cancer. ${ }^{5}$ Together, these data indicate that smoking cessation reduces total mortality by a third to a half and that the greatest and most immediate impact is on CVD endpoints. The survival effects on COPD- and lung cancer-related mortality are more variable and complex.

\section{Tobacco treatment and hospitalization}

Of the 5887 patients studied in the LHS, 754 patients (representing $12.8 \%$ of the cohort) experienced at least one hospitalization during the 5 years of follow-up and 282 patients (representing 4.8\% of the cohort and 37.4\% of those hospitalized at least once) had two or more hospitalizations.${ }^{17} \mathrm{CVD}$ accounted for $42 \%$ of the first and $48 \%$ of the second hospitalizations. Coronary heart disease was responsible for $75 \%$ of all CVD hospitalizations. In the INTERHEART study, current smoking was associated with a three-fold increase in the risk for nonfatal acute MI. ${ }^{21}$ The relationship was dose-dependent such that those who smoked

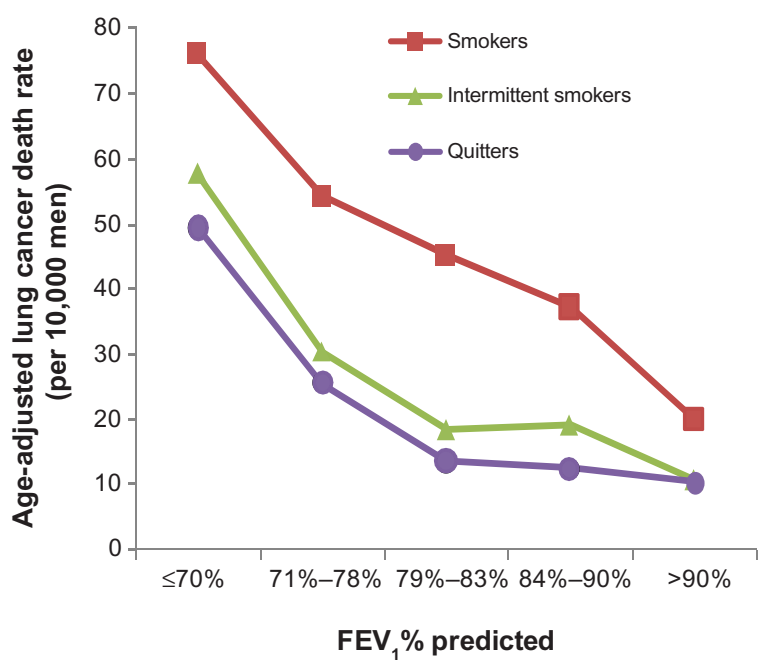

Figure I The relation of lung function and lung cancer mortality in men according to smoking status in the MRFIT Study. ${ }^{20}$ At all FEV , values, the risk of lung cancer mortality is higher in smokers than in intermittent smokers/quitters and sustained quitters. In quitters and intermittent smokers, the risk of lung cancer mortality in men rises substantially below $\mathrm{FEV}_{1}$ of $80 \%$ of predicted.

Abbreviations: $\mathrm{FEV}_{1}$, forced expiratory volume in one second; MRFIT, Multiple Risk Factor Intervention Trial. 
a pack per day or more (20+ cigarettes per day) had a 4.6fold increase in the risk compared with never smokers. ${ }^{22}$ The relationship was also age-dependent, such that younger smokers (50 years of age or younger) had significantly higher risk of nonfatal MI than older smokers who smoked the same number of cigarettes per day. ${ }^{22}$ The risk declines with smoking cessation. The greatest decline in risk occurs within the first 3 years of smoking abstinence. ${ }^{22}$ Overall, the population attributable risk of acute MI related to cigarette smoking is $36 \%,{ }^{21}$ making it the single most important modifiable risk factor for this endpoint. In comparison, diabetes mellitus and hypertension, two other leading modifiable risk factors, contribute only $10 \%$ and $18 \%$, respectively, to the total population-attributable risk of acute MI. ${ }^{21}$

\section{General benefits of smoking cessation in patients with asthma}

Patients with asthma also benefit from tobacco treatment as smoking cessation is associated with improved lung function, enhanced quality of life, and decreased reliance on rescue inhalers. ${ }^{23,24}$ Smoking cessation also reduces airway inflammation. ${ }^{23,25}$

\section{Benefits of smoking cessation in patients with asthma}

Tobacco smoke contains many compounds that are noxious and carcinogenic to the airway. Not surprisingly, the prevalence of asthma is higher in current and former smokers compared with never-smokers. ${ }^{26}$ Regrettably, despite the detrimental effects of smoking on asthma, the prevalence of smoking in asthmatics is comparable to that in the general population. ${ }^{27}$ The risk of developing asthma is greater among current smokers than in ex-smokers or occasional smokers, especially amongst females. ${ }^{28}$ Among asthmatics, smoking is associated with increased symptoms, ${ }^{29}$ more frequent exacerbations, ${ }^{30}$ and emergency department visits, ${ }^{31}$ and higher health care costs. Smoking is also associated with accelerated decline in lung function ${ }^{32}$ and increased mortality. ${ }^{33}$

There is another important mechanism by which smoking can adversely affect asthmatics. It is now well established that the most effective pharmacologic treatment for asthma is inhaled corticosteroid. ${ }^{34}$ Smoking, however, promotes corticosteroid-insensitivity and attenuates their effectiveness $^{35}$ by possibly downregulating histone deacetylase ${ }^{36}$ and enhancing neutrophil-mediated airway inflammation. ${ }^{37}$ Together, these effects may make the inflammation in asthma less susceptible to corticosteroids .
Smoking is a modifiable risk factor and an important target in the treatment of asthma. A study by Chaudhuri and colleagues showed significant short-term improvements on lung function after smoking cessation. ${ }^{25} \mathrm{~A}$ recent study by Jang and colleagues showed similar findings. ${ }^{23}$ Interestingly, in this study, the salutary effects of smoking cessation on lung function were greater than that achieved by high-dose oral prednisolone. Smoking cessation also led to a reduction in sputum neutrophils. In a study by Tonnesen, asthmatic patients who managed to quit smoking experienced significant improvements in their quality of life, daytime symptoms, and bronchial hyper-reactivity. They also had decreased reliance on rescue inhalers. ${ }^{24}$ Together, these data indicate that smoking cessation is essential in the management of patients with asthma.

\section{Benefits of tobacco treatment in patients with established lung cancer}

In the Western nations, smoking is responsible for $90 \%$ of all cases of lung cancer. ${ }^{38}$ The risk of dying from lung cancer is 22 times higher in male smokers and 12 times higher in female smokers compared with never smokers. ${ }^{4}$ Smoking cessation is associated with improved outcomes even among patients diagnosed with lung cancer. A recent meta-analysis found that in patients who are diagnosed with early stage non-small cell lung cancer (NSCLC), smoking cessation reduced total mortality by $66 \%$ and the risk of recurrence or a second lung primary by $46 \%$ compared with continued smokers. ${ }^{39}$ The data were similar in patients with small cell lung cancer (SCLC). In patients with established SCLC, smoking cessation decreased total mortality by $46 \%$ and the risk of a recurrence or a second lung primary by $77 \% .{ }^{39}$ Collectively, these data suggest that among patients diagnosed with early to mid stages of NSCLC and SCLC, smoking cessation is still beneficial and prolongs survival and reduces the rate of recurrence of tumor and/or second lung primaries.

\section{Smoking cessation in patients with established CVD}

Smoking cessation improves health outcomes in patients who have experienced MI and developed mild left ventricular (LV) systolic dysfunction. In Survival and Ventricular Enlargement (SAVE), which evaluated 2231 subjects with LV dysfunction 3-16 days following their MI, smoking cessation at 6-month follow-up reduced all-cause mortality by $43 \%$, the risk of death or recurrent MI by $32 \%$, and death or heart failure hospitalization by $35 \% .{ }^{40}$ In comparison, in the same trial, 
captopril, an angiotensin-converting-enzyme inhibitor, was demonstrated to reduce total mortality by $19 \%$, recurrent MI rate by $25 \%$, and heart failure hospitalization rate by $22 \%{ }^{41}$ Together, these data indicate the critical importance of smoking cessation in promoting good health outcomes in patients with previous history of MI.

\section{Side effects of smoking cessation}

There are very few side effects of smoking cessation. The most common is weight gain. ${ }^{42}$ In the LHS, the average weight gain in the first year following smoking cessation was $5 \mathrm{~kg}$ for both men and women. ${ }^{42}$ When expressed as percentage of baseline weight, women gained more weight than did men. The average weight gain in the first year following smoking cessation was $8 \%$ (above baseline weight) in women and $6 \%$ for men.

\section{Interventions to promote smoking cessation?}

Most smokers are motivated to quit smoking. In the US and UK, nearly three out of four workers intend to quit smoking every year, yet fewer than $5 \%$ are able to quit successfully on their own. ${ }^{43,44}$

\section{Predictors of smoking cessation}

There are some clinical factors that have been associated with increased abstinence rate in patients with COPD. These include: enrolling in intensive smoking cessation programs consisting of repeated counseling sessions and pharmacotherapy, ${ }^{7}$ which increases the odds for smoking cessation 4.4-fold; older age; and having smoked a fewer number of cigarettes over their lifetime. COPD disease severity, on the other hand, is not associated with increased rates of smoking cessation.

\section{Public policy}

Smoking restrictions in public places, work places, and households are a very effective way of promoting abstinence. However, despite compelling evidence of efficacy, fewer than $10 \%$ of countries mandate smoke-free bars and restaurants, and more than 60 countries have no smoke-free policies whatsoever. ${ }^{3}$ Raising prices on tobacco products is another effective means of increasing smoking cessation. There is good evidence to indicate that when the price of cigarettes increase by more than $10 \%$, the rate of abstinence increases by $3 \%{ }^{3}$ Complete advertising bans on tobacco is also effective, reducing smoking rates by $6 \% .^{3}$ Although vitally important, these public health measures are not enough for the $20 \%-25 \%$ of adults who are addicted to nicotine and continue to smoke. Additional measures are needed to treat these patients' addictions.

\section{Nonpharmacologic interventions}

Patients who try to quit smoking on their own rarely achieve complete abstinence over time. Initially, $25 \%-50 \%$ of patients succeed; however, by 3 months, the success rate drops off to only $10 \%-20 \%$, and by 6 months, $95 \%-97 \%$ of those who tried are back smoking. ${ }^{45}$ In general, both pharmacotherapies and nonpharmacotherapies are needed to significantly impact smoking cessation rates.

Smokers with COPD behave similarly to healthy smokers when it comes to smoking cessation. Over 12 months, the average complete abstinence rate in the COPD population is approximately $1.4 \%,{ }^{46}$ though there is a large variation in the rates reported in the literature. However, the addition of intensive counseling sessions increases quit rates to about $6.0 \%$. The institution of pharmacotherapy on top of intensive counseling doubles the cessation rate to $12.3 \%{ }^{46}$ Minimal counseling, defined as counseling sessions that last less than 90 minutes, on the other hand, does not materially affect abstinence rates $(2.6 \%) .{ }^{46}$ The addition of pharmacologic agent to counseling is synergistic, resulting in a two- to three-fold increase in the rate of smoking cessation compared with usual care, or a 1.8fold increase in smoking cessation compared with counseling alone. ${ }^{47}$ The use of nicotine replacement therapy in lieu of an antidepressant medication results in similar cessation rates as that achieved by antidepressant drugs.

Informing smokers that they have COPD slightly increases the rate of smoking cessation. ${ }^{48}$ However, once patients are diagnosed with COPD, showing them their abnormal spirometry data does not enhance smoking cessation rates. ${ }^{49,50}$ If the spirometry data are conveyed in the form of "lung age" rather than in liters or as a percent of predicted, patients are more likely to understand the severity of their lung function impairment and thus more likely to quit smoking. ${ }^{51}$ Lung age is defined as the age of the average person with an $\mathrm{FEV}_{1}$ equal to the patient. The use of lung age in communicating the results of lung function tests of smokers results in a two-fold increase in the complete abstinence rate at 12 months compared with the standard approach of using liters or percentage of predicted values in communicating abnormal spirometry results $(13.6 \%$ versus $6.4 \% ; P=0.01) .{ }^{51}$

\section{Pharmacotherapy to effect tobacco treatment}

In general, among COPD patients, the use of pharmacotherapy is superior to nonpharmacotherapy in effecting 
complete abstinence rates, ${ }^{52}$ and disease severity does not modify cessation rates. The effectiveness of various pharmacotherapies for smoking cessation is shown in Figure 2. In general, bupropion and varenicline are more effective than nicotine replacement therapy (NRT) (Figure 2) and are more cost-effective than NRT (Figure 3). ${ }^{53}$ Pharmacotherapies for smoking cessation are highly cost-effective across all age groups (Figure 3)..$^{53}$ The addition of behavior therapy to pharmacotherapy alone is not cost-effective..$^{53}$

\section{NRT}

Smokers are addicted to nicotine.${ }^{54}$ Cigarettes are an effective means of delivering nicotine quickly to the brainstem where it stimulates the release of dopamine via the nicotinic receptors. NRT aims to take away the cravings for cigarettes and mitigate nicotine withdrawal symptoms by providing steady stimulation to the nicotinic receptors and preventing the rapid fluctuations in the release of dopamine in the forebrain..$^{53,54}$ NRT is safe, because unlike cigarettes NRT does not contain thousands of nonnicotine products contained in cigarettes. NRT comes in various forms, including as a transdermal patch, gum, lozenge, inhaler, sublingual tablet, and nasal spray. They have similar efficacy in promoting abstinence, increasing the rate two-fold compared with placebo. ${ }^{53}$ The results are similar in patients with COPD. One randomized controlled trial found that the use of nicotine sublingual tablets resulted in a significantly higher 1-year complete abstinence rate compared with placebo ( $14 \%$ versus $5 \%$; odds ratio [OR] 2.86; $P<0.0001) .{ }^{52}$ However, in general, the use of NRT for hospitalized patients with smoking-related conditions does not appear to increase smoking cessation rates above counseling alone. ${ }^{55,56}$ The reasons for this observation are uncertain.

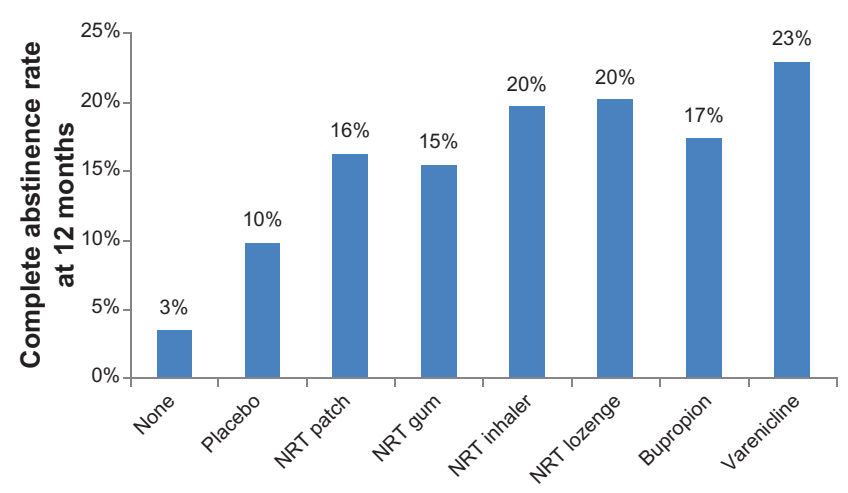

Figure 2 Effectiveness of various pharmacotherapies in promoting complete smoking cessation at one year of follow-up. Data derived from Beasley. ${ }^{68}$ Abbreviation: NRT, nicotine replacement therapy.

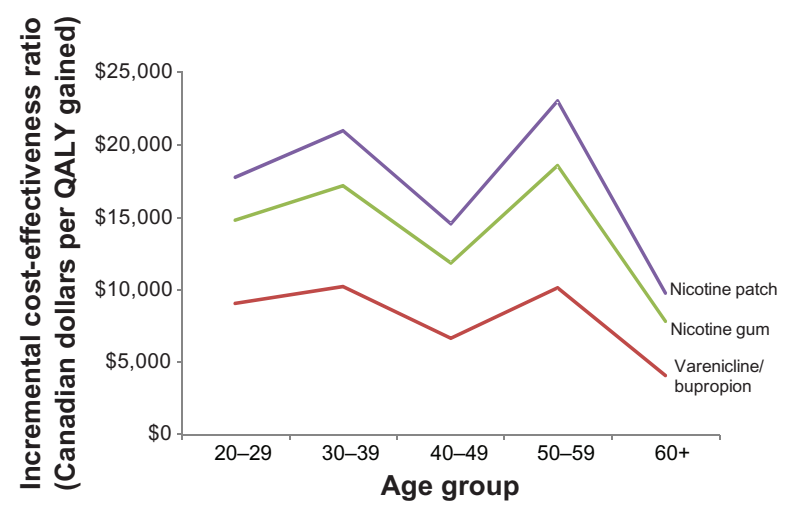

Figure 3 Incremental cost-effectiveness ratio of various pharmacotherapies in promoting smoking cessation according to age group of smokers. Data derived from Beasley. ${ }^{68}$ The cost-effectiveness ratios of varenicline and bupropion are nearly identical.

Abbreviation: QALY, quality adjusted life-years.

\section{Bupropion}

Antidepressants, in particular bupropion, are commonly used to increase smoking cessation rates. ${ }^{57}$ Bupropion is an atypical antidepressant that inhibits the re-uptake of norepinephrine and dopamine in the brain. The most serious side effects of this medication are seizures, which occur very infrequently. ${ }^{57}$ Accordingly, patients with a pre-existing seizure condition should not be prescribed this medication. The recommended starting adult dose is $150 \mathrm{mg}$ per day for 3 days and then increasing to $300 \mathrm{mg}$ per day. ${ }^{58}$ In COPD, bupropion is a very effective smoking cessation aid, increasing the 6-month complete abstinence rate approximately two-fold compared with placebo. ${ }^{59,60}$ Similar to NRT, the use of bupropion in hospitalized patients with smoking-related conditions does not appear to increase smoking cessation rates above that achieved by counseling. ${ }^{61,62}$ Together, these data suggest that smokers with COPD at any disease severity can be treated with bupropion for 12 weeks with the expectation that approximately $15 \%-20 \%$ of these smokers will achieve complete abstinence by 6 months without experiencing significant side effects from the medications.

\section{Varenicline}

Varenicline is a nicotinic receptor agonist that binds to alpha- 4 beta- 2 receptor as well as to alpha- 3 beta- 4 , alpha-3 beta-2, alpha-6, and alpha-7 nicotinic receptors. ${ }^{63}$ By weakly binding to these receptors, it causes an attenuated release of dopamine in the forebrain, while at the same time preventing the binding of these receptors to nicotine. The usual recommended dosage of varenicline for adults is $0.5 \mathrm{mg}$ once daily for 3 days, followed by $0.5 \mathrm{mg}$ twice daily for 4 days, and then 
Table I Seminal studies evaluating the effect of tobacco treatment on cardiopulmonary health outcomes

\begin{tabular}{|c|c|c|}
\hline Study (reference number) & Sample size & Study findings \\
\hline The Lung Health Study $y^{6,7}$ & 5887 & $\begin{array}{l}\text { In patients with mild to moderate COPD, tobacco treatment was associated with reduced } \\
\text { disease progression and risk of hospitalization and mortality. Women derived larger benefits } \\
\text { from smoking cessation than male smokers. }\end{array}$ \\
\hline $\begin{array}{l}\text { Multiple Risk Factor } \\
\text { Intervention Trial (MRFIT) }{ }^{18,69}\end{array}$ & 12,866 & Smoking cessation reduced mortality from lung cancer. \\
\hline INTERHEART study ${ }^{21}$ & 29,972 & $\begin{array}{l}\text { Current smoking is the single most important modifiable risk factor for reducing the risk of } \\
\text { acute myocardial infarction, increasing the relative risk three-fold compared with nonsmokers. }\end{array}$ \\
\hline $\begin{array}{l}\text { Survival and Ventricular } \\
\text { Enlargement (SAVE) study }\end{array}$ & 2231 & $\begin{array}{l}\text { In patients with left ventricular dysfunction after a recent acute myocardial infarction, smoking } \\
\text { cessation reduced mortality, risk of recurrent myocardial infarction, hospitalization from } \\
\text { congestive heart failure, and death. The benefit of smoking cessation was greater than that } \\
\text { related to the use of an angiotensin converting enzyme inhibitor. }\end{array}$ \\
\hline
\end{tabular}

Abbreviation: COPD, chronic obstructive pulmonary disease.

$1 \mathrm{mg}$ twice daily for the remaining portion of the 12-week treatment regimen.$^{63}$ Common side effects in the general population are nausea, abdominal cramps, and sleep disorders including nightmares. Although suicidal ideation and major depression are very uncommon, varenicline is best avoided in patients who have a history of major depression or an anxiety disorder. ${ }^{63}$ The effect of varenicline was recently reported in the COPD population. In this trial of patients with mild to moderate COPD (average $\mathrm{FEV}_{1}$ of $70 \%$ of predicted), the use of varenicline for 12 weeks was associated with a complete abstinence rate of $42 \%$ at 3 months of therapy compared with only $9 \%$ in the placebo group (OR 8.40; $P<0.0001)$. However, by 52 weeks of follow-up, the rate of abstinence decreased to about $19 \%$ in the varenicline treated group and to $6 \%$ in the placebo group (OR 4.04; $P<0.0001$ ). ${ }^{64}$ Serious adverse effects related to this medication were rare, occurring in approximately $3 \%$ of the patients. However, minor side effects such as nausea (occurring in $27 \%$ of treated patients), and abnormal dreams (occurring in $11 \%$ of treated patients), and other sleep disturbances (eg, insomnia) were relatively common. ${ }^{64}$

\section{Other respiratory benefits of tobacco treatment}

Along with lung cancer and COPD, smoking has also been associated with nonspecific ground-glass opacification and centrilobular nodularity on computed tomography scans of the chest, which correspond pathologically to respiratory bronchiolitis. Some patients with this condition are symptomatic with coughing and shortness of breath, but many may be relatively asymptomatic. ${ }^{65}$ Physiologically, these patients may have normal spirometry but almost have reduced diffusing capacity for carbon monoxide. Both the radiographic and physiologic changes may improve significantly following smoking cessation. ${ }^{66}$ Smoking has also been associated with fibrotic lung conditions such as idiopathic pulmonary fibrosis, respiratory bronchiolitis-interstitial lung disease (RB-ILD), desquamative interstitial pneumonitis, and rheumatoid arthritis-associated interstitial lung disease, ${ }^{67}$ and also with Langerhans cell histiocytosis. ${ }^{65}$ The benefits of smoking cessation have not been well studied in these conditions. However, most lung transplantation programs across the world insist on smoking cessation before considering these patients for lung transplant, which can be life-preserving for patients with end-stage or severe smoking-related fibrotic lung disease.

\section{Conclusion}

Smoking is responsible for one in five deaths worldwide. Although the prevalence of smoking is declining in the Western world, the worldwide prevalence is on the rise, owing largely to increasing rates in developing nations. It is estimated that one in three Chinese men below the age of 30 years will die from smoking-related diseases unless smoking rates dramatically decrease over the next few years. In patients with established COPD, the benefits of smoking cessation are immense, regardless of severity. In mild to moderate COPD, smoking cessation reduces the risk of disease progression as well as the risk for lung cancer and CVD, which collectively are the leading causes of morbidity and mortality in this population of patients. In more severe cases, smoking cessation reduces total mortality. In patients with established CVD, smoking cessation is more powerful in reducing the recurrence of CVD events and total mortality than any pharmacological intervention currently in use. For patients with early NSCLC or SCLC, smoking cessation improves survival and attenuates the risk of recurrence or development of a second primary lung cancer. Together, these data provide a compelling rationale 
for aggressively promoting tobacco treatment through public health policy and smoking cessation programs. The use of bupropion and varenicline in appropriate patients is costeffective in fostering complete abstinence.

\section{Acknowledgments/disclosure}

This work is supported by the Canadian Institutes of Health

\section{Research.}

DDS is a senior scholar with the Michael Smith Foundation for Health Research and a Canada Research Chair in COPD.

\section{References}

1. Ezzati M, Lopez AD. Estimates of global mortality attributable to smoking in 2000. Lancet. Sep 13 2003;362(9387):847-852.

2. World Health Organization. World Health Report 2002. Geneva, Switzerland: WHO; 2002.

3. World Health Organization. WHO Report on the Global Tobacco Epidemic 2009: Implementing Smoke-free Environments. Geneva, Switzerland: WHO; 2009.

4. US Department of Health and Human Services. The health benefits of smoking cessation: a report of the Surgeon General. Betheseda, MD: US Public Health Service, Office on Smoking and Health; 1990.

5. Anthonisen NR, Skeans MA, Wise RA, Manfreda J, Kanner RE, Connett JE. The effects of a smoking cessation intervention on 14.5-year mortality: a randomized clinical trial. Ann Intern Med. 2005;142(4):233-239.

6. Connett JE, Murray RP, Buist AS, et al. Changes in smoking status affect women more than men: results of the Lung Health Study. Am J Epidemiol. 2003;157(11):973-979.

7. Anthonisen NR, Connett JE, Kiley JP, et al. Effects of smoking intervention and the use of an inhaled anticholinergic bronchodilator on the rate of decline of FEV1. The Lung Health Study. JAMA. 1994;272(19):1497-1505.

8. Kohansal R, Martinez-Camblor P, Agusti A, Buist AS, Mannino DM, Soriano JB. The natural history of chronic airflow obstruction revisited: an analysis of the Framingham offspring cohort. Am J Respir Crit Care Med. 2009;180(1):3-10.

9. Fletcher C, Peto R. The natural history of chronic airflow obstruction. Br Med J. 1977;1(6077):1645-1648.

10. Lundback B, Lindberg A, Lindstrom M, et al. Not 15 but $50 \%$ of smokers develop COPD? Report from the Obstructive Lung Disease in Northern Sweden Studies. Respir Med. 2003;97(2):115-122.

11. Mannino DM, Buist AS, Petty TL, Enright PL, Redd SC. Lung function and mortality in the United States: data from the First National Health and Nutrition Examination Survey follow up study. Thorax. 2003;58(5):388-393.

12. Buist AS, McBurnie MA, Vollmer WM, et al. International variation in the prevalence of COPD (the BOLD Study): a population-based prevalence study. Lancet. 2007;370(9589):741-750.

13. Wilson D, Adams R, Appleton S, Ruffin R. Difficulties identifying and targeting COPD and population-attributable risk of smoking for COPD: a population study. Chest. 2005;128(4):2035-2042.

14. Coultas DB, Howard CA, Peake GT, Skipper BJ, Samet JM. Salivary cotinine levels and involuntary tobacco smoke exposure in children and adults in New Mexico. Am Rev Respir Dis. 1987;136(2):305-309.

15. Anthonisen NR, Connett JE, Murray RP. Smoking and lung function of Lung Health Study participants after 11 years. Am J Respir Crit Care Med. 2002;166(5):675-679.

16. Murray RP, Anthonisen NR, Connett JE, et al. Effects of multiple attempts to quit smoking and relapses to smoking on pulmonary function. Lung Health Study Research Group. J Clin Epidemiol. 1998;51(12):1317-1326.
17. Anthonisen NR, Connett JE, Enright PL, Manfreda J. Hospitalizations and mortality in the Lung Health Study. Am J Respir Crit Care Med. 2002;166(3):333-339.

18. Multiple Risk Factor Interventional Trial Study Group. Mortality after 16 years for participants randomized to the Multiple Risk Factor Intervention Trial. Circulation. 1996;94(5):946-951.

19. Wasswa-Kintu S, Gan WQ, Man SF, Pare PD, Sin DD. Relationship between reduced forced expiratory volume in one second and the risk of lung cancer: a systematic review and meta-analysis. Thorax. 2005;60(7):570-575.

20. Eberly LE, Ockene J, Sherwin R, Yang L, Kuller L. Pulmonary function as a predictor of lung cancer mortality in continuing cigarette smokers and in quitters. Int J Epidemiol. 2003;32(4):592-599.

21. Yusuf S, Hawken S, Ounpuu S, et al. Effect of potentially modifiable risk factors associated with myocardial infarction in 52 countries (the INTERHEART study): case-control study. Lancet. 2004;364(9438): 937-952.

22. Teo KK, Ounpuu S, Hawken S, et al. Tobacco use and risk of myocardial infarction in 52 countries in the INTERHEART study: a case-control study. Lancet. 2006;368(9536):647-658.

23. Jang AS, Park SW, Kim DJ, et al. Effects of smoking cessation on airflow obstruction and quality of life in asthmatic smokers. Allergy Asthma Immunol Res. 2010;2(4):254-259.

24. Tonnesen P, Pisinger C, Hvidberg S, et al. Effects of smoking cessation and reduction in asthmatics. Nicotine Tob Res. 2005;7(1):139-148.

25. Chaudhuri R, Livingston E, McMahon AD, et al. Effects of smoking cessation on lung function and airway inflammation in smokers with asthma. Am J Respir Crit Care Med. 2006;174(2):127-133.

26. Krzyzanowski M, Robbins DR, Lebowitz MD. Smoking cessation and changes in respiratory symptoms in two populations followed for 13 years. Int J Epidemiol. 1993;22(4):666-673.

27. Lemiere C, Boulet LP. Cigarette smoking and asthma: a dangerous mix. Can Respir J. 2005;12(2):79-80.

28. Piipari R, Jaakkola JJ, Jaakkola N, Jaakkola MS. Smoking and asthma in adults. Eur Respir J. 2004;24(5):734-739.

29. Stallberg B, Lisspers K, Hasselgren M, Johansson G, Svardsudd K. Factors related to the level of severity of asthma in primary care. Respir Med. 2007;101(10):2076-2083.

30. Siroux V, Pin I, Oryszczyn MP, Le Moual N, Kauffmann F. Relationships of active smoking to asthma and asthma severity in the EGEA study. Epidemiological study on the Genetics and Environment of Asthma. Eur Respir J. 2000;15(3):470-477.

31. Strine TW, Balluz LS, Ford ES. The associations between smoking, physical inactivity, obesity, and asthma severity in the general US population. J Asthma. 2007;44(8):651-658.

32. O'Byrne PM, Lamm CJ, Busse WW, Tan WC, Pedersen S. The effects of inhaled budesonide on lung function in smokers and nonsmokers with mild persistent asthma. Chest. 2009;136(6):1514-1520.

33. Lange P, Parner J, Vestbo J, Schnohr P, Jensen G. A 15-year follow-up study of ventilatory function in adults with asthma. $N$ Engl $J$ Med. 1998;339(17):1194-1200.

34. Fanta CH. Asthma. N Engl J Med. 2009;360(10):1002-1014.

35. Lazarus SC, Chinchilli VM, Rollings NJ, et al. Smoking affects response to inhaled corticosteroids or leukotriene receptor antagonists in asthma. Am J Respir Crit Care Med. 2007;175(8):783-790.

36. Ito K, Lim S, Caramori G, Chung KF, Barnes PJ, Adcock IM. Cigarette smoking reduces histone deacetylase 2 expression, enhances cytokine expression, and inhibits glucocorticoid actions in alveolar macrophages. FASEB J. 2001;15(6):1110-1112.

37. Chalmers GW, MacLeod KJ, Thomson L, Little SA, McSharry C, Thomson NC. Smoking and airway inflammation in patients with mild asthma. Chest. 2001;120(6):1917-1922.

38. Alberg AJ, Samet JM. Epidemiology of lung cancer. Chest. 2003;123 (1 Suppl):21S-49S.

39. Parsons A, Daley A, Begh R, Aveyard P. Influence of smoking cessation after diagnosis of early stage lung cancer on prognosis: systematic review of observational studies with meta-analysis. BMJ. 2010;340:b5569. 
40. Shah AM, Pfeffer MA, Hartley LH, et al. Risk of all-cause mortality, recurrent myocardial infarction, and heart failure hospitalization associated with smoking status following myocardial infarction with left ventricular dysfunction. Am J Cardiol. 2010;106(7):911-916.

41. Pfeffer MA, Braunwald E, Moye LA, et al. Effect of captopril on mortality and morbidity in patients with left ventricular dysfunction after myocardial infarction. Results of the survival and ventricular enlargement trial. The SAVE Investigators. N Engl J Med. 1992;327(10):669-677.

42. Wise RA, Enright PL, Connett JE, et al. Effect of weight gain on pulmonary function after smoking cessation in the Lung Health Study. Am J Respir Crit Care Med. 1998;157(3 Pt 1):866-872.

43. Cigarette smoking among adults - United States, 2000. MMWR Morb Mortal Wkly Rep. 2002;51(29):642-645.

44. Leatherdale ST, Shields M. Smoking cessation: intentions, attempts and techniques. Health Rep. Sep 2009;20(3):31-39.

45. Hughes JR, Keely J, Naud S. Shape of the relapse curve and long-term abstinence among untreated smokers. Addiction. 2004;99(1):29-38.

46. Hoogendoorn M, Feenstra TL, Hoogenveen RT, Rutten-van Molken MP. Long-term effectiveness and cost-effectiveness of smoking cessation interventions in patients with COPD. Thorax. 2010;65(8):711-718.

47. Strassmann R, Bausch B, Spaar A, Kleijnen J, Braendli O, Puhan MA. Smoking cessation interventions in COPD: a network meta-analysis of randomised trials. Eur Respir J. 2009;34(3):634-640.

48. Stratelis G, Molstad S, Jakobsson P, Zetterstrom O. The impact of repeated spirometry and smoking cessation advice on smokers with mild COPD. Scand J Prim Health Care. 2006;24(3):133-139.

49. Bize R, Burnand B, Mueller Y, Rege Walther M, Cornuz J. Biomedical risk assessment as an aid for smoking cessation. Cochrane Database Syst Rev. 2009;(2):CD004705.

50. Kotz D, Wesseling G, Huibers MJ, van Schayck OC. Efficacy of confronting smokers with airflow limitation for smoking cessation. Eur Respir J. 2009;33(4):754-762.

51. Parkes G, Greenhalgh T, Griffin M, Dent R. Effect on smoking quit rate of telling patients their lung age: the Step2quit randomised controlled trial. BMJ. 2008;336(7644):598-600.

52. Tonnesen P, Mikkelsen K, Bremann L. Nurse-conducted smoking cessation in patients with COPD using nicotine sublingual tablets and behavioral support. Chest. 2006;130(2):334-342.

53. Tran K, Asakawa K, Cimon K, et al. Pharmacologic-based Strategies for Smoking Cessation: Clinical and Cost-Effectiveness Analyses Ottawa: Canadian Agency for Drugs and TechnologiesinHealth;2010.(TechnologyReport;no.130). [cited2010-09-21]. Available from: http://www.cadth.ca/index.php/en/hta/reports-publications/search?\&type=16. Accessed 11 Feb 2011.

54. Benowitz NL. Nicotine addiction. $N$ Engl J Med. 2010;362(24) 2295-2303.
55. Lewis SF, Piasecki TM, Fiore MC, Anderson JE, Baker TB. Transdermal nicotine replacement for hospitalized patients: a randomized clinical trial. Prev Med. 1998;27(2):296-303.

56. Westman EC, Levin ED, Rose JE. The nicotine patch in smoking cessation. A randomized trial with telephone counseling. Arch Intern Med. 1993;153(16):1917-1923.

57. Jorenby DE, Leischow SJ, Nides MA, et al. A controlled trial of sustained-release bupropion, a nicotine patch, or both for smoking cessation. N Engl J Med. 1999;340(9):685-691.

58. Rigotti NA. Clinical practice. Treatment of tobacco use and dependence. N Engl J Med. 2002;346(7):506-512.

59. Tashkin D, Kanner R, Bailey W, et al. Smoking cessation in patients with chronic obstructive pulmonary disease: a double-blind, placebocontrolled, randomised trial. Lancet. 2001;357(9268):1571-1575.

60. Wagena EJ, Knipschild PG, Huibers MJ, Wouters EF, van Schayck CP. Efficacy of bupropion and nortriptyline for smoking cessation among people at risk for or with chronic obstructive pulmonary disease. Arch Intern Med. 2005;165(19):2286-2292.

61. Rigotti NA, Thorndike AN, Regan S, et al. Bupropion for smokers hospitalized with acute cardiovascular disease. Am J Med. 2006; 119(12):1080-1087.

62. Simon JA, Duncan C, Huggins J, Solkowitz S, Carmody TP. Sustainedrelease bupropion for hospital-based smoking cessation: a randomized trial. Nicotine Tob Res. 2009;11(6):663-669.

63. Hays JT, Ebbert JO. Varenicline for tobacco dependence. N Engl J Med 2008;359(19):2018-2024.

64. Tashkin DP, Rennard S, Hays JT, Ma W, Lawrence D, Lee TC. Effects of varenicline on smoking cessation in mild-to-moderate COPD A randomized controlled trial. Chest. 2010 Sep 23. [Epub before print].

65. Beasley MB. Smoking-related Small airway disease - a review and update. Adv Anat Pathol. 2010;17(4):270-276.

66. Nakanishi M, Demura Y, Mizuno S, et al. Changes in HRCT findings in patients with respiratory bronchiolitis-associated interstitial lung disease after smoking cessation. Eur Respir J. 2007, 29(3):453-461.

67. Vassallo R, Ryu JH. Tobacco smoke-related diffuse lung diseases. Semin Respir Crit Care Med. 2008;29(6):643-650.

68. Beasley MB. Smoking-related small airway disease - a review and update. Adv Anat Pathol. 2010;17(4):270-276.

69. The Multiple Risk Factor Intervention Trial Research Group. Mortality after 16 years for participants randomized to The Multiple Risk Factor Intervention Trial Research Group. Circulation. 1996;94(5):946-951.
International Journal of COPD

\section{Publish your work in this journal}

The International Journal of COPD is an international, peer-reviewed journal of therapeutics and pharmacology focusing on concise rapid reporting of clinical studies and reviews in COPD. Special focus is given to the pathophysiological processes underlying the disease, intervention programs, patient focused education, and self management protocols.

\section{Dovepress}

This journal is indexed on PubMed Central, MedLine and CAS. The manuscript management system is completely online and includes a very quick and fair peer-review system, which is all easy to use. Visi http://www.dovepress.com/testimonials.php to read real quotes from published authors. 